\title{
Paisaje agrario en contextos periurbanos \\ mediterráneos: el caso del Gran Sousse (Túnez)
}

\author{
Agricultural landscape in periurban mediterranean contexts: \\ the case of Greater Sousse (Tunis)
}

\begin{abstract}
Abdelkarim Hamrita
abdelkarimhamrita@gmail.com

I'ISA-IRESA

Université de Sousse (Túnez)

\section{Rafael Mata-Olmo}

rafael.mata@uam.es
\end{abstract}

Departamento de Geografía

Universidad Autónoma de Madrid (España)

\section{Nieves López-Estébanez \\ nieves.lopez@uam.es \\ Departamento de Geografía \\ Universidad Autónoma de Madrid (España)}

\author{
Hichem Rejeb \\ hrejeb0962@gmail.com \\ I'ISA-IRESA \\ Université de Sousse (Túnez)
}




\title{
Resumen
}

La protección de la agricultura periurbana mediante la zonificación de determinados suelos como no urbanizables por los instrumentos de planificación urbanística y territorial resulta insuficiente frente a las fuertes presiones de usos residenciales, industriales, infraestructurales y, en ocasiones, turísticos que provocan su fragilidad. En este texto se aborda la potencialidad del paisaje para activar este tipo de agricultura que se desenvuelve bajo influencia urbana directa y se adopta el Landscape Character Assessment como metodología sistemática de identificación y caracterización de los paisajes de la agricultura periurbana del Gran Sousse, la principal aglomeración urbana y turística del Sahel tunecino, con objeto de su evaluación, ordenación y promoción. Se adopta la noción de carácter del paisaje y se relaciona con las políticas públicas de gestión de los espacios agrarios periurbanos tunecinos y la percepción social, mediante entrevistas a una muestra de actores locales y regionales. Se analiza la diversidad paisajística concretada en Áreas Paisajísticas de Agricultura Periurbana (APAP), caracterizadas a partir de su particular fisonomía, y de los principales elementos y funcionamiento pasado y presente. El estudio concluye con la propuesta de un proyecto de paisaje como infraestructura verde, que implica un modelo de gestión de conflictos de acuerdo con las necesidades propias del paisaje, de los agricultores y de la población que lo percibe y lo utiliza como espacio abierto, fortaleciendo su función de productor de alimentos de calidad y de proximidad, como un ejercicio de participación y gobernanza territorial.

Palabras clave: agricultura periurbana; multifuncionalidad; carácter del paisaje; proyecto de paisaje; gobernanza.

\begin{abstract}
The protection of peri-urban agriculture through the zoning of certain land as undevelopable by urban and spatial planning instruments is insufficient in the face of strong pressures from residential, industrial, infrastructural and sometimes tourist uses that make it fragile. This text addresses the potential of landscape to activate this type of agriculture under direct urban influence and applies the Landscape Character Assessment as a systematic methodology for the identification and characterisation of peri-urban agricultural landscapes in Greater Sousse, the main urban and tourist agglomeration in the Tunisian Sahel, with a view to their evaluation, management and promotion. The notion of landscape character is adopted and related to public policies for the management of Tunisian peri-urban agricultural spaces and social perception, through interviews with a sample of local and regional actors. Landscape diversity is analysed in
\end{abstract}


the form of Periurban Agricultural Landscape Areas (PALA), characterised on the basis of their particular physiognomy, and their main elements and past and present functioning. The study concludes with the proposal of a landscape project as green infrastructure, which implies a conflict management model in accordance with the needs of the landscape, of the farmers and of the population that perceives and uses it as an open space, strengthening its function as a producer of quality and proximity food, as an exercise of participation and territorial governance.

Key words: periurban agriculture; multifunctionality; landscape character; landscape project; governance.

\section{Una agricultura viva para un paisaje periurbano de calidad}

La agricultura y los agricultores son, en muchos entornos urbanos y metropolitanos de las dos orillas del Mediterráneo, actores fundamentales de la gestión del pasado y el presente del paisaje y, con frecuencia, de su propia identidad. Una agricultura viva e innovadora - sin entender la innovación como el mero aumento de la productividad, sino como fomento de la calidad alimentaria, de la producción de proximidad y la eficiencia y armonización de sus múltiples funciones- es en sí misma una garantía de calidad paisajística periurbana y, a la vez, de desarrollo económico sostenible. Los paisajes rurales periurbanos, con predominio todavía hoy de formas y funciones agropecuarias, a las que se suman nuevos usos y demandas sociales, constituyen un excelente ámbito para el conocimiento y el proyecto paisajístico (Donadieu, 2009; Mata-Olmo, 2015; Sabaté, 2015).

Se trata de espacios en una situación paradójica y contradictoria: dominan aún en extensión en numerosos entornos urbanos del Mediterráneo, pero en general cuentan con pocos actores agrarios, frente a muchos agentes y usuarios no agrarios, que en unos casos presionan por el cambio de uso del suelo y, en otros, por el acceso público al disfrute del paisaje y el mantenimiento de los servicios de los agroecosistemas (Mata-Olmo, 2011). Por lo tanto, son paisajes vividos, percibidos y valorados de modos contrapuestos y hasta conflictivos, planteando así un claro reto de gobernanza (Donadieu, 2009).

Además, y por encima de diferencias entre lugares, muchos paisajes rurales periurbanos, por razones ambientales e históricas, albergan en su configuración, en su funcionamiento y en infinidad de prácticas sociales (Mata-Olmo, 2004), numerosas huellas, representaciones y símbolos de significado patrimonial (Silva Pérez, 2010), incluso en el caso de conjuntos paisajísticos transformados y deteriorados, como ocurre con las huertas y viejos regadíos 
históricos inmersos en la evolución de las aglomeraciones urbanas (Branduini \& Scazzosi, 2011; Hermosilla Pla, 2010; Romero \& Francés, 2012; Paül Carril \& Haslam McKenzie, 2013; Yacamán \& Mata, 2017) . Estos paisajes agrarios ubicados a las puertas de la ciudad o salpicando los tejidos metropolitanos, sin más valores que su propio carácter e identidad, y su condición de espacios libres, con suelos habitualmente fértiles y alta capacidad de producción de alimentos, constituyen la auténtica arena de la calidad de vida y la sostenibilidad de nuestras ciudades, un reto de civilización para sociedades devoradoras de territorio. Como bien dice Giorgio Agamben, "hoy no es la ciudad sino el campo el paradigma biopolítico fundamental del Occidente" (Agamben, 1998, citado en Mostafavi, 2010).

El renovado sentido conceptual y estratégico de paisaje que preconiza el Convenio Europeo del Paisaje (Consejo de Europa, 2000) puede y debe ser un buen camino para el reencuentro entre dos formas de uso, organización y vivencia del territorio: la de la ciudad, con funciones económicas y residenciales intensivas, y la de los espacios abiertos que la rodean, habitualmente agrícolas, aunque calificados genéricamente y de modo equívoco en muchos planes urbanísticos como suelos no urbanizables protegidos por su interés ambiental.

Tras décadas de expansión urbana poco atenta a los valores y funciones del entorno rural, los planteamientos actuales del urbanismo y la ordenación del territorio conceden un papel cada vez más importante a los espacios abiertos periurbanos, en la búsqueda de un proyecto territorial compartido entre campo y ciudad. En las regiones urbanas, la agricultura es ahora reconocida y legitimada, tras ser ignorada durante largo tiempo, como una valiosa forma de ocupación del suelo, pero rara vez como actividad económica y como el modo de ganarse la vida de las personas que la practican. Se plantea así un reto genuino de gobernanza, consistente en incorporar a los agricultores y a las políticas agrarias en un proyecto de paisaje periurbano vivo, multifuncional y de calidad. El diálogo campo-ciudad debe materializarse en la concertación entre actores, con presencia significativa de los agricultores, y en la cooperación de políticas sectoriales, concretamente de la política agroalimentaria, habitualmente ausente en la planificación de los espacios periurbanos, con objeto de construir proyectos agrourbanos (Bryant, 1997; Poulot, 2014; Yacamán, Sanz \& Mata, 2019: 91 y ss.).

Estudios recientemente publicados y nuestra propia experiencia en proyectos de paisaje en entornos urbanos y metropolitanos en Túnez y España ponen de manifiesto que sin incorporar la agricultura como actividad económica y a los agricultores, las propuestas de ordenación del suelo no urbanizable y los alegatos a favor del paisaje no suelen ir más allá, en el mejor de los 
casos, de zonificaciones de protección convencionales, de futuro dudosamente viable sin gestión agrícola. A esa conclusión llegaron hace años Giulia Giacchè y Chiara Mazzocchi tras analizar el escaso reconocimiento del papel de la agricultura en los instrumentos de planificación territorial italianos, incluso en alguno específicamente paisajístico como el Piano Territoriale Paesístico Regionale del Lazio (Giacché \& Mazzocchi, 2011). En Francia, un país con larga experiencia en la consideración de la actividad agraria en la ordenación del territorio y el paisaje, el concurso de ideas organizado en su momento para la ordenación de una ciudad científica en Saclay (île de France), con la condición de mantener 2.000 ha de agricultura en su entorno, puso de manifiesto la dificultad que tenían los urbanistas para integrar esa realidad. "Unos han creado simplemente una nueva frontera, otros, una demarcación utópica; sólo algunos de los 26 equipos concursantes han sabido adoptar un punto de vista de 'coconstrucción' territorial. Eso remite -opinan Roland Vidal y André Fleury, arquitecto y agrónomo, respectivamente- a la formación de los urbanistas, que ignoran las lógicas sistémicas de los espacios abiertos" (Vidal \& Fleury, 2009).

Dos factores juegan hoy, como señalan también Vidal y Fleury, a favor de la reinserción de la agricultura en la lógica urbana. El primero consiste en que, en países de vieja cultura agraria como los de las riberas del Mediterráneo, la agricultura continúa siendo un aspecto importante de las identidades locales, regionales y hasta nacionales (piénsese en los casos de las huertas de Murcia y Valencia en España, los olivares del Sahel o las huertas del cabo Bonn en Túnez). El segundo, de aparición más reciente, es el aumento de la conciencia del coste ambiental de la distancia en el aprovisionamiento alimentario - la cuenta de los food miles-, que, junto a la frescura, la calidad y la identidad del producto de proximidad, abre o refuerza las potencialidades de una agricultura multifuncional periurbana y una nueva geografía de la seguridad alimentaria (Sonnino, 2016). Se recuperan así, en un nuevo contexto de lucha contra el urban sprwal, la búsqueda de calidad y la eficiencia agrícola y, a la vez, la salvaguarda y disfrute público del paisaje, principios y objetivos de un urbanismo agrario -agriurbanism en expresión de Charles Waldheim - que, en la mejor tradición urbanística de la segunda mitad del siglo XIX y primera del XX, pretendieron armonizar las relaciones entre agricultura y ciudad (Waldheim, 2010).

Son numerosas las iniciativas de activación de la agricultura periurbana que en los últimos tiempos se han puesto en marcha, tanto en el mundo desarrollado (Sazada, 2011; Lohrberg et al., 2016), como en algunos países en vías de desarrollo (Veenhuizen, 2009). En este texto interesan particularmente las llevadas a cabo en Francia, donde se cuenta con una larga 
trayectoria metodológica y aplicada, materializada desde fines de los años noventa en el denominado agriurbanisme y le project agriurbain (Fleury \& Donadieu, 1997; Fleury, 2006; Vidal \& Fleury, 2009), con experiencias muy interesantes en Île de France (Poulot, 2014) y en una serie de ciudades medias y grandes integradas en la red Terres en villes (terresenvilles.org). En Italia, en esa misma línea, aunque con especificidades propias, constituye un referente bien conocido el Parque Agrario del Sur de Milán, inspirador en Cataluña de la iniciativa pionera del Parque Agrario del Baix Llobregat (Callau \& Paül, 2007; Paül, 2015; Roda, 2015; Sabaté, 2015), replicada en otros parques agrarios catalanes o en la más reciente Parque Agrario de Fuenlabrada (Mata-Olmo \& Yacamán Ochoa, 2015), que pueden servir de referencia para proyectos similares en el periurbano turístico del Gran Sousse.

A partir del enfoque de la nueva geografía de la alimentación (Heynen, 2012), el proyecto agrourbano pretende mejorar la resiliencia del metabolismo urbano mediante la puesta en marcha de políticas que revaloricen el sistema de espacios abiertos desde un enfoque botton-up. Como ha señalado Yacamán (2017), el proyecto agrourbano parte de la preocupación ciudadana por un medio ambiente saludable y un paisaje de calidad y responde a las demandas de aprovisionamiento alimentario con productos locales (Pasini et al., 2012). Uno de los principales objetivos del paradigma del proyecto agrourbano es el apoyo y la puesta en valor de la multifuncionalidad de la agricultura periurbana (producción de alimentos locales, frescos y de temporada, generación de empleo, gestión de paisajes y promotor de identidad, etc.) y la protección de los espacios agrarios donde se desarrolla su actividad. El paisaje vivo y gestionado se convierte en un punto de encuentro entre agricultores y residentes urbanos en torno a una alimentación sana y de proximidad. De esta forma, el proyecto agrourbano materializa el deseo de reconexión campo-ciudad para lograr un funcionamiento sistémico del territorio (Bernard et al., 2012).

En ese contexto teórico y de renovado interés estratégico por la agricultura periurbana y sus múltiples funciones, en particular, las de producción de alimentos y gestión de paisajes de calidad, este texto tiene por objeto el estudio de la agricultura periurbana de la aglomeración del Gran Sousse, la tercera región metropolitana más poblada y extensa de Túnez. Lo hace con un enfoque paisajístico, siguiendo las directrices que plantea el Convenio Europeo del Paisaje adaptado a la realidad tunecina, con el objetivo de caracterizar los distintos agrosistemas y paisajes que conviven en la aglomeración, diagnosticar sus múltiples funciones, valores y problemas, y formular un proyecto de paisaje en torno a la figura de parque agrario. El proyecto de paisaje pretende ir más allá de la mera protección territorial del espacio de la agricultura 
periurbana y promover la revitalización de la función productora agroalimentaria de calidad y proximidad de unos suelos agrarios de elevada fertilidad sobre los que se ha construido históricamente un paisaje de alto interés patrimonial. El proyecto requiere, a través del paisaje, de un ejercicio de gobernanza, con la participación e implicación de los principales actores, de los agricultores en primer lugar, de los poderes locales y regionales y de la ciudadanía socialmente organizada.

\section{Características de la agricultura periurbana del Gran Sousse (Túnez)}

Las llanuras costeras mediterráneas han sido consideradas paradigma de la fertilidad y la diversidad agrícola, con un rico patrimonio material e inmaterial ligado a la organización secular de la agricultura y, en particular, al uso y gestión del agua. Al norte del Mediterráneo y, concretamente, en el sur y este de España, las huertas, nacidas en buena medida del ingenio y saber hacer de los musulmanes, creadores del complejo y sofisticado sistema hidráulico que, mejorado y ampliado después, las riega aún hoy, constituyen el exponente más notable del paisaje de una agricultura periurbana regada con altos valores agroecológicos, productivos, culturales y paisajísticos (Hermosilla, 2010; Mata \& Fernández, 2010).

Como al norte, en el sur del Mediterráneo el paisaje más característico de las llanuras costeras del Magreb y de algunos valles medios y bajos interiores son los regadíos históricos, de estrecho parentesco andalusí con numerosos sistemas costeros ibéricos levantinos y meridionales. En el caso de Túnez, y particularmente en la llanura costera central del Sahel tunecino, el paisaje agrario de secanos y regadíos temporales y permanentes constituye la expresión material y simbólica de mayor significado de una agricultura vinculada históricamente al consumo de pueblos y villas costeras, modernizada tras la independencia del país con fuerte intervención pública para abastecer los mercados urbanos en expansión y la demanda internacional, especialmente europea, y sometida hoy a similares procesos de deterioro y presión urbana que en el Mediterráneo europeo por el crecimiento paralelo de determinadas aglomeraciones urbanas y del turismo litoral de masas. Son parecidos los debates y retos que estas agriculturas periurbanas de la costa tunecina suscitan a los que tienen lugar en España, con la salvedad de que en Túnez la producción agrícola desempeña aún un papel significativo de abastecimiento local y familiar para un colectivo importante y numeroso de explotaciones campesinas.

Ese es el contexto en el que se enmarca este estudio de la agricultura periurbana en la aglomeración del Gran Sousse, con un claro énfasis en las manifestaciones paisajísticas de los 
agrosistemas locales regados y el compromiso con un proyecto de paisaje que preserve y revitalice una agricultura de alto significado estratégico tanto productivo como ambiental y cultural en un espacio urbano-turístico de alta demanda en productos agrícolas frescos, crecientemente saturado y con necesidad también de recualificar y diversificar su oferta turística de sol y playa.

Sousse (Susa en castellano), antigua Handrumete, es una de las villas litorales presente desde la antigüedad en la historia urbana de Túnez (Houimili, 2008) (Figura 1). Fundada por los fenicios, como Útica y Cartago, su estratégica posición en el centro de la costa oriental tunecina favoreció, tras etapas de cierto esplendor en épocas romana, bizantina y arabo-musulmana (fue puerto de Kairouán durante varios siglos), su desarrollo como ciudad europeizada, capital del Sahel tunecino bajo colonización francesa, con un desarrollo urbano contemporáneo en torno a la medina y hacia el puerto ampliado y modernizado, de indudable interés urbanístico y arquitectónico (Ben Saïd, 1985).

Figura 1. Localización del área de estudio: Túnez, Gobernación de Sousse, Grand Sousse y municipios del Grand Sousse
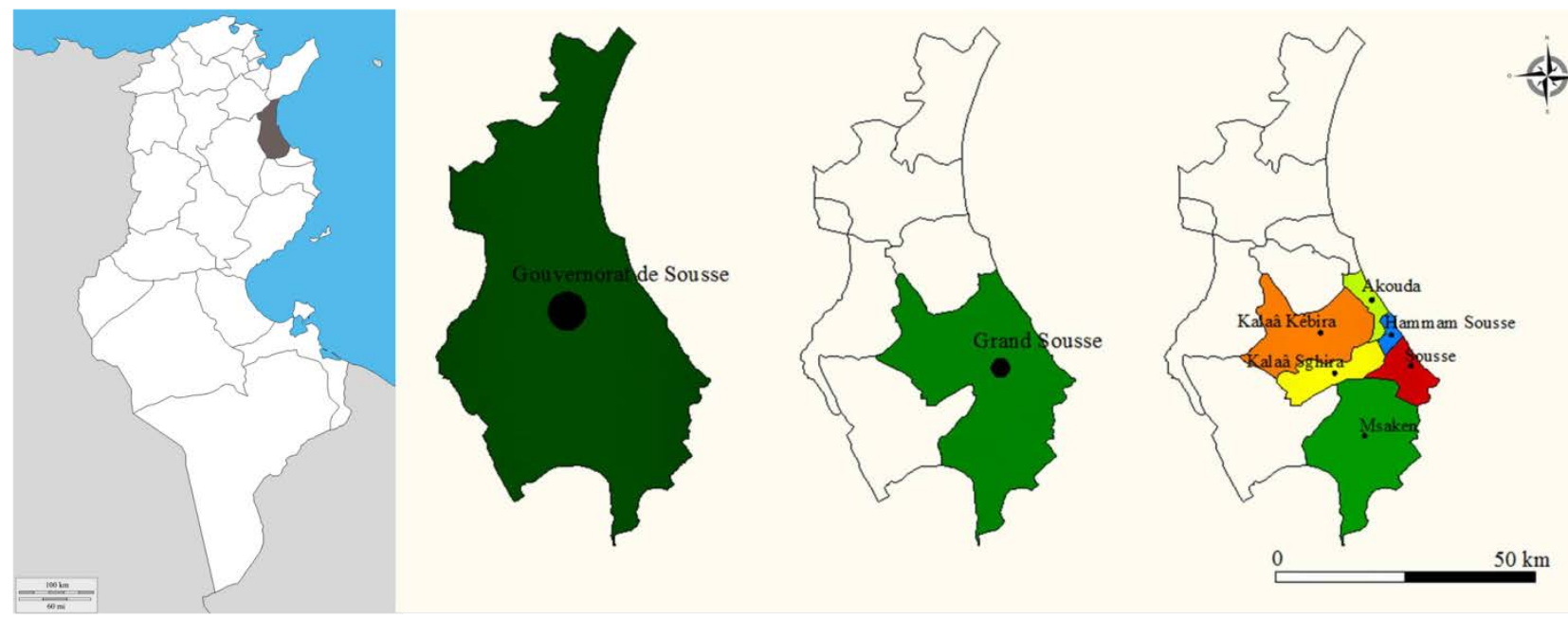

Fuente: elaboración propia

La antigua ciudad colonial francesa se convierte, desde la independencia, en uno de los polos de atracción de las políticas públicas de modernización económica del nuevo régimen de Habib Burguiba, dirigidas tanto al sector industrial y turístico, que encuentra en el litoral de Sousse a Monastir uno de los ámbitos preferentes de actuación de la Agence Foncière Touristique (AFT) para el turismo de masas, como a la agricultura, a través de los planes de modernización de riegos públicos que se tratarán a continuación. 
El crecimiento demográfico y espacial de la urbanización residencial y turística resultan espectaculares por su cuantía y celeridad. La población de Sousse y su aglomeración en ciernes se duplican en algo más de 20 años, acercándose a los 700000 habitantes en 2019 (tercera área metropolitana de Túnez, tras la capital y Sfax), cuando apenas superaba los 200000 a comienzos de los 80 del pasado siglo. El núcleo central de la aglomeración, Sousse, irradia aumentos demográficos y funciones urbanas sobre un número importante de municipios vecinos, en particular sobre los de Msaken, Kalaâ Kébira, Kalaâ Sghira, Akouda, Hammam Sousse, este último conurbado ya con la capital.

Al crecimiento de estos núcleos se suma el del espacio turístico ex novo, planificado en parte por la AFT ya a comienzos de los años 70 del siglo pasado. La urbanización litoral se desarrolla a expensas de la agricultura y la naturaleza, replicando experiencias de la costa española. Las dunas y las huertas situadas al norte de la capital son los primeros espacios naturales y agrícolas en acoger los complejos hoteleros, infraestructuras y equipamientos planificados por la AFT. La instalación del complejo turístico y portuario de El Kantaoui favorece a su vez la periurbanización residencial, planificada o informal, del espacio agrícola interior, que, junto con el desarrollo de las infraestructuras ocupa y fragmenta una extensa zona regada en la que coexisten enclaves tradicionales y áreas de regadíos públicos recientemente creadas (Jaouachi, 2016). El hábitat residencial espontáneo e informal, que constituye en los últimos años el proceso más destructor, y la presión y ofertas de los inversores en los últimos tres decenios -antes del freno habido en los últimos años de revolución e inestabilidad política- han hecho muy frágil y vulnerable la agricultura de proximidad y numerosos propietarios han debido abandonar sus tierras, ganando terreno los suelos de erial agrícola en espera de urbanización.

La incapacidad de los planes territoriales y municipales para ordenar estos procesos desenfrenados de ocupación y desarticulación de la agricultura ha sido flagrante. Sin embargo, la percepción generalizada entre los técnicos locales y departamentales de la necesidad de preservar y activar estas piezas agrícolas de tanto valor productivo y patrimonial, y el aprecio por estos paisajes en ciertas capas de la población urbana y turística (Hamrita, 2017) han conducido al análisis prospectivo de la agricultura periurbana del Gran Sousse, incidiendo en su dimensión paisajística y en la formulación de un proyecto de paisaje, mediador entre campo y ciudad, entre agricultores y residentes urbanos y turistas, entre agricultura, alimentación de calidad y servicios ecosistémicos, en particular los denominados servicios paisajísticos (Termorshuizen \& Opdam, 2009; Bastian et al., 2014), para estos espacios estratégicos de la agricultura periurbana de la aglomeración. 
El espacio agrario hoy periurbano ha sido objeto en Túnez, y en el área del gran Sousse en concreto, de numerosas políticas de desarrollo agrícola, como la de "Zonas de riego público", de claro paralelismo con la de "Zonas regables de alto interés nacional" del INC (Instituto Nacional de Colonización) y el IRYDA (Instituto de Reforma y Desarrollo Agrario) en la España de los años 50-70 del siglo XX, para incrementar y modernizar la producción agraria y reducir la dependencia alimentaria del país y, también, para conquistar los mercados exteriores. Los factores fundamentales para la conservación y el impulso de los regadíos periurbanos de numerosos países mediterráneos, entre ellos Túnez y España, son el gran potencial de los recursos hidrológicos, edáficos y climáticos de las llanuras costeras mediterráneas, que merecen ser preservados y activados, no solo mediante técnicas de modernización convencional, sino atendiendo a la calidad de la producción y a los valores patrimoniales del lugar, para contribuir a satisfacer la demanda creciente de alimentos sanos y próximos, y la calidad ambiental de las regiones urbanas (Ben Attia, 2015). La movilización de recursos hídricos, la reforma y el desarrollo agrario en la segunda mitad del siglo XX en Túnez contribuyeron a transformar un paisaje tradicional, claramente agrario en su momento, en uno moderno que se desenvuelve ahora en un contexto periurbano de gran fragilidad, crecientemente ocupado por una urbanización sin vuelta atrás (Donadieu \& Fleury, 1997). En el caso del Gran Sousse, la política agraria debe ser abordada actualmente en primer lugar como instrumento de protección del espacio de la olivicultura y las huertas y de los paisajes que construyen y gestionan; y, en segundo lugar, como instrumento de creación e impulso de un nuevo sistema de producción agraria intensiva, así como de un paisaje vivo, con memoria y carácter, en un contexto periurbano con una fuerte expansión poblacional y urbana, y un sector turístico en desarrollo.

Por otra parte, debe tenerse en cuenta también que la agricultura periurbana del Gran Sousse presenta hoy dos perfiles con diferentes funciones. El primero es el de la agricultura periurbana alimentaria, al mismo tiempo comercial y patrimonial; el segundo perfil es el de una agricultura con escasa función alimentaria, con una finalidad principalmente turística y de mantenimiento de un entorno agradable, que viene desarrollándose desde hace algunos años en las inmediaciones del espacio turístico. El primer tipo, que es el que interesa en este artículo, está integrado por las huertas tradicionales familiares como las senias y las zonas de riegos públicos, que contribuye al aprovisionamiento de la ciudad con frutas y verduras frescas y de calidad, mediante diversas formas de comercialización (mercados, venta directa, en la calle]) (Meddeb, 2009). En ese tipo se incluyen también la agricultura de secano con cultivos herbáceos, forrajeros y frutales pluviales (olivo, almendra, higueral), así como la de riego en explotaciones 
frutícolas intensivas (cítricos, melocotoneros, perales, granados】), localizada también en las zonas de riegos públicos o privados (Rejeb, 2011), que proporciona productos alimentarios destinados a la región o al intercambio extra-regional (Houimli, 2008). El segundo grupo corresponde, como se ha dicho, a la agricultura no alimentaria, destinada al agroturismo y preferentemente orientada a la provisión de nuevos servicios ambientales, sociales y paisajísticos.

\section{Metodología}

\subsection{Aproximación conceptual: el Convenio Europeo del Paisaje}

La indagación contemporánea sobre la noción de paisaje, en particular la aplicable a los paisajes de la agricultura periurbana, habitualmente banales, con signos extendidos de deterioro y abandono, sin perjuicio de sus múltiples valores, conduce a la definición consensuada y establecida por el Convenio Europeo del Paisaje (CEP) (Consejo de Europa, 2000). El CEP entiende el paisaje como "cualquier parte del territorio, tal y como la percibe la población, cuyo carácter sea el resultado de la acción y la interacción de factores naturales y/o humanos" (traducción del Instrumento de Ratificación del Convenio Europeo del Paisaje, BOE de 5 de febrero de 2008). Aunque se trata de una convención internacional referida al ámbito europeo, sus planteamientos son asumibles en un país en vías de desarrollo como Túnez, al igual que ha ocurrido en los últimos años en América Latina, donde se ha puesto en marcha la Iniciativa Latinoamericana del Paisaje (LALI), inspirada en los principios y planteamientos del CEP. El paisaje se concibe como el carácter del territorio - de cada territorio- percibido por la población, es decir, como el conjunto de rasgos y cualidades que lo identifican y diferencian de otros paisajes, la expresión material y percibida de su identidad (Mata-Olmo, 2014).

En la propia definición y en la de su "ámbito de aplicación", el CEP no se restringe a los territorios paisajísticamente valiosos, sino que se aplica "a todo el territorio (abarcando) las áreas naturales, rurales, urbanas y periurbanas". Cualquier territorio, cada parte del mismo, se manifiesta en un paisaje y se percibe paisajísticamente. Todos los paisajes resultan, pues, de interés y son importantes. Este es el mensaje más renovador del Convenio y su compromiso mayor. Por eso la política que preconiza no es meramente reactiva o protectora de lo notable; es sobre todo proactiva, dirigida a todos los paisajes, a los sobresalientes y a los banales, a los cotidianos y a los visitados, a la calidad del entorno vital de las personas (Mata-Olmo, 2014). Porque -lo señala el "Informe explicativo" en su apartado 44- todos los paisajes "son determinantes para la calidad de los espacios vividos por las poblaciones", en especial, los paisajes cotidianos u ordinarios, en los que vive la mayor parte de las personas. Esas son las 
razones que hacen del Convenio Europeo del Paisaje, de su concepción y agenda pública, una referencia obligada para el análisis y el proyecto de paisaje de los territorios de agricultura periurbana y, en particular, para los de la región urbana de Sousse.

\subsection{Caracterización y cualificación paisajística}

Asumido el entendimiento renovado de paisaje del CEP y sus directrices para la acción y el proyecto de protección, gestión y mejora de los paisajes, la tarea previa e imprescindible es la de su caracterización y cualificación. Muy escasa es la experiencia en Túnez en este tipo de trabajos, pese a la influencia francesa en materia de paisaje en disciplinas como la geografía, la agronomía, el urbanismo o la arquitectura. Para la identificación y caracterización de la diversidad paisajística del periurbano del gran Sousse se ha seguido de cerca, con matices, la propuesta metodológica de Landscape Character Assessment (LCA) (Swanwick, 2002; Tudor, 2014; Zoido Naranjo \& Ortega Delgado, 2010; Fernández, 2015), sin desconocer las notables contribuciones de los atlas departamentales franceses, sobre todo en materia iconográfica y en la atención que han prestado a los paisajes de la agricultura y a los periurbanos en particular (Ambroise et al., 2001). El carácter del paisaje adquiere en el LCA un papel relevante tanto en la caracterización del paisaje como en su cualificación y en lo que respecta a la toma de decisiones. La secuencia metodológica del LCA ha permitido integrar en el proceso de caracterización datos cuantitativos, cualitativos y cartográficos (de gabinete y de terreno) de los componentes naturales y, sobre todo, culturales del paisaje, con especial atención a los que intervienen en la identificación y configuración de los agrosistemas periurbanos, así como los resultados de las entrevistas en profundidad a actores locales, técnicos de las administraciones públicas locales y provinciales, y a los agricultores, así como del público en general.

\subsection{Tipología y taxonomía paisajística}

La integración de componentes y procesos generadores del paisaje agrario periurbano del Gran Sousse, incluida su organización visual y distribución espacial, ha permitido formular una tipología jerarquizada del paisaje, inédita hasta ahora en Túnez, con vocación clara de servir de base al proyecto paisajístico (Project paysagère) para la planificación territorial y local dentro de los instrumentos reglados en la ordenación del territorio tunecino. Se trata de una taxonomía multiescalar que distingue e integra tres niveles de análisis (tipo, subtipo y área de paisaje), construida en la práctica de abajo a arriba, pero que puede ser leída en sentido inverso. Por otra parte, cada subtipo se concreta y expresa en unas denominadas áreas paisajísticas de agricultura periurbana (APAP), que constituyen manifestaciones específicas de cada uno de los 
subtipos por su ubicación, morfología y visibilidad, y que, en general, se asocian a realidades locales (municipales) distintas.

Por otra parte, la metodología aplicada al espacio agrario periurbano, estructurado por la trilogía de la olivicultura, la arboricultura frutícola y las hortalizas, ha permitido distinguir también entre una agricultura periurbana tradicional y otra moderna o modernizada en relación con los sistemas e infraestructuras de riego. No obstante, el régimen comercial o de autoconsumo no está necesariamente ligado al carácter tradicional o moderno del agrosistema, aunque los regadíos modernizados por iniciativa pública están mayoritariamente orientados al mercado, en tanto que en la agricultura tradicional coexisten las producciones de autoconsumo con las destinadas al mercado local y regional. Sobre esta base se realiza un análisis detallado de una de las Áreas Paisajísticas de Agricultura Periurbana delimitadas.

\section{Clasificación del paisaje del Gran Sousse y su caracterización}

El resultado de aplicar la metodología propuesta por el LCA ha sido una taxonomía de paisajes que presenta las siguientes características (Figura 2): el nivel superior, al que siguiendo la terminología LCA se ha denominado tipo de paisaje, está constituido por el "Paisaje agrario periurbano del Gran Sousse", que responde, en líneas generales, al tipo paisajístico de las agriculturas periurbanas litorales tunecinas; forman parte del tipo un total de cinco subtipos, que aun presentando los rasgos y procesos característicos del paisaje agrario periurbano, constituyen configuraciones tipológicas diferenciadas por su génesis histórica y funciones tradicionales, y por la percepción social que merecen, tanto de técnicos y expertos como de la población en general: Senia (Figura 3), Ghars, Perímetro público irrigado, Ghaba y Sebkhat, este último de dominante natural, aunque con aprovechamiento humano tradicional.

\section{Figura 2. Esquema taxonómico paisajístico del Gran Sousse}

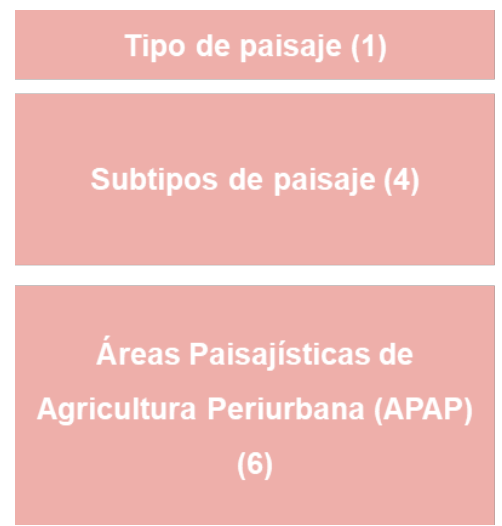

\section{Paisaje agrario periurbano del Gran Sousse}

\section{Senia}

Ghars

Perimetro público irrigado

Ghaba

Sebkhat

Senia

Ghars

Ghaba

Zona de riego público de Chott Mariem

Zona de riego público de Chott Romain

Zona de riego público de Zaouia-Ksiba-Thrayet

Fuente: elaboración propia 
Por último, se caracterizaron seis Áreas Paisajísticas de Agricultura Periurbana (APAP) a partir de criterios, elementos, funcionamiento y percepción del paisaje (Tabla 1).

\section{Tabla 1. Áreas Paisajísticas de Agricultura Periurbana (APAP)}

\begin{tabular}{|c|c|c|}
\hline $\begin{array}{c}\text { ORGANIZACIÓN GENERAL, } \\
\text { COMPONENTES Y ELEMENTOS } \\
\text { PAISAJIISTICOS }\end{array}$ & $\begin{array}{c}\text { FUNCIONAMIENTO Y DINÁMICAS } \\
\text { PAISAJIISTICAS }\end{array}$ & CARÁCTER DE PAISAJE \\
\hline \multicolumn{3}{|c|}{ APAP SENIA (Figura 2) } \\
\hline $\begin{array}{l}\text { Huerta tradicional dedicada a la } \\
\text { fruticultura y la horticultura } \\
\text { Parcelario pequeño }(<3 \text { ha) y } \\
\text { heterogéneo, que se organiza de } \\
\text { manera lineal siguiendo el curso de } \\
\text { los ouedes. } \\
\text { Explotaciones cercadas con tapias y } \\
\text { regadas con agua de pozos } \\
\text { superficiales, marcados por } \\
\text { palmeras. } \\
\text { Acequias sin revestimiento como } \\
\text { infraestructura y sistema de riego } \\
\text { tradicional. }\end{array}$ & $\begin{array}{l}\text { Sistemas de producción combinada de } \\
\text { policultivo tradicional y ganadería poco } \\
\text { intensiva. } \\
\text { Predomino de la unidad familiar en la } \\
\text { propiedad y la gestión de la explotación. } \\
\text { Consumo eminentemente familiar y algo de } \\
\text { excedentes. } \\
\text { Modos de comercialización diversos (en la } \\
\text { finca, en mercado local y regional). } \\
\text { Reducción progresiva de la actividad } \\
\text { agrícola, venta de la tierra y cambio del } \\
\text { uso de suelo agrario al urbano. }\end{array}$ & $\begin{array}{l}\text { Sistemas de producción } \\
\text { integrada de policultivo } \\
\text { (arboricultura + hortalizas) } \\
\text { tradicional y una ganadería } \\
\text { poco intensiva y familiar, con } \\
\text { las acequias como sistema de } \\
\text { riego tradicional y combinando } \\
\text { diversos modos de } \\
\text { comercialización en el } \\
\text { mercado local, regional y a pie } \\
\text { de finca. }\end{array}$ \\
\hline \multicolumn{3}{|c|}{ APAP GHARS } \\
\hline $\begin{array}{l}\text { Huerta tradicional de secano que } \\
\text { ocupa el espacio intermedio entre la } \\
\text { ciudad y la APAP Ghaba. } \\
\text { Parcelario muy pequeño (< } 1 \text { ha), } \\
\text { heterogéneo, cercado con tapias y } \\
\text { articulado por una red de caminos } \\
\text { de baja densidad. }\end{array}$ & $\begin{array}{l}\text { Propiedad privada y gestión familiar de la } \\
\text { explotación. } \\
\text { Olivos, almendros e higueras son los } \\
\text { arboles típicos de este tipo de huerta. } \\
\text { Sistema de producción tradicional } \\
\text { caracterizado por la fruticultura de secano. } \\
\text { Productos dedicados al consumo familiar. } \\
\text { Regeneración del arbolado. } \\
\text { Pérdida intensa y desaparición acelerada } \\
\text { de la actividad agrícola. } \\
\text { Evolución hacia un espacio sin cultivo y } \\
\text { urbano. }\end{array}$ & $\begin{array}{l}\text { Sistemas de producción } \\
\text { tradicionales dominados por la } \\
\text { "fruticultura de secano" sobre } \\
\text { un parcelario minifundista en } \\
\text { torno a una red de caminos de } \\
\text { poca densidad. Huerto cerrado } \\
\text { con tapia plantada de setos de } \\
\text { chumberas y agave con } \\
\text { policultivo arbóreo } \\
\text { característico (olivo, almendra } \\
\text { e higuera), complementado } \\
\text { con modesta avicultura para el } \\
\text { consumo familiar. }\end{array}$ \\
\hline \multicolumn{3}{|c|}{ APAP Ghaba } \\
\hline $\begin{array}{l}\text { Corresponde al gran "bosque" de } \\
\text { olivos saheliano de la región. } \\
\text { El olivo constituye el elemento } \\
\text { fundamental del área de paisaje. } \\
\text { El meskat es el sistema de riego } \\
\text { temporal tradicional compuesto de } \\
\text { dos componentes: La hamada (zona } \\
\text { alta de colinas ordenada para } \\
\text { acopiar el agua de lluvia) y el } \\
\text { mankaa, que corresponde a las } \\
\text { terrazas de plantaciones. } \\
\text {-Parcelario de tamaño pequeño. }\end{array}$ & $\begin{array}{l}\text { Sistemas de producción tradicional de } \\
\text { oleicultura de secano. } \\
\text { Cultivo extensivo con una estrecha relación } \\
\text { con el buen estado del sistema de riego } \\
\text { temporal (meskat) } \\
\text { Práctica de ganadería poco intensiva. } \\
\text { Propiedad privada y familiar. } \\
\text { Gestión familiar de las explotaciones. } \\
\text { Cultivo en primer lugar destinado al } \\
\text { consumo familiar y en segundo lugar al } \\
\text { mercado local y regional. } \\
\text { Envejecimiento de los árboles y } \\
\text { fragmentación del parcelario. }\end{array}$ & $\begin{array}{l}\text { Sistemas de producción } \\
\text { extensivos de olivicultura y } \\
\text { ganadería poco intensiva. } \\
\text { Ausencia de cerramientos de } \\
\text { las parcelas y persistencia de } \\
\text { un sistema de riego tradicional } \\
\text { y esporádico conocido como } \\
\text { meskat. Los parcelarios son } \\
\text { morfológicamente } \\
\text { heterogéneos y minifundistas, y } \\
\text { el cultivo es alimentario, } \\
\text { familiar y patrimonial, y, en } \\
\text { parte, comercial. }\end{array}$ \\
\hline
\end{tabular}




\section{Tabla 1. Continuación}

\section{APAP ZRP de Chott Mariem}

\begin{tabular}{l|l} 
Huerta litoral tradicional pero & Técnicas de riego y de producción
\end{tabular} modernizada desde los años 60, irrigada con el agua de la presa de Nabhana en el centro del país.

Parcelario de tamaño mediano (> 3 ha $y<5$ ha).

El olivo constituye el componente principal del sistema de cultivo, aunque no el único.

Cultivo de hortaliza temprana.

Explotaciones multilocalizadas. Urbanización vacacional entre tierras de cultivo. modernas.

Explotaciones arrendadas por la mayoría de los agricultores

Propiedad privada y familiar, con frecuente separación entre propiedad y explotación a través de arrendamientos y aparcerías. Fuerte desarrollo de la actividad inmobiliaria para uso residencial y turístico. Venta de los productos al mercado regional.
Cinturón hortícola modernizado del norte y este de la región de estudio, limítrofe a las zonas residenciales y turísticas.

Explotaciones de parcelario disperso, de tamaño mediano y organizadas por una red de caminos con setos de ciprés.

\section{APAP "ZRP de Chott Romain}

Huerta de fruticultura tradicional modernizada y Localizada en las llanuras del oued Laya.

Granado como cultivo característico.

Parcelario de tamaño mediano a pequeño ( $<3$ ha)

Pozos marcados por las palmeras

\section{Explotaciones con funcionamiento} tradicional.

Orientación al cultivo de forrajeras y ganadería intensiva.

Propiedad privada y familiar. Abandono progresivo de la actividad agrícola y ganadera, venta de tierras y cambio del uso del suelo.

Desarrollo de la urbanización residencial.

\section{APAP "ZRP de Zaouia-Ksiba-Thrayet"}

Olivos tradicionales irrigados con aguas residuales, localizados al suroeste de la ciudad de Sousse. El olivo constituye el elemento fundamental del área de paisaje. Parcelario de tamaño pequeño $<3$ ha.

Sistema de riego tradicional mediante acequias.
Sistemas de producción combinada: olivicultura, forraje y ganadería poco intensiva.

Propiedad privada y familiar. Gestión familiar de las explotaciones. Técnicas de riego y de producción tradicionales.

Venta de la producción en el mercado local y en la finca.
Sistemas de producción combinada de olivicultura, forraje y ganadería poco intensiva sobre un parcelario heterogéneo privado de tamaño mediano a pequeño, irrigado con aguas residuales tratadas.

Fuente: elaboración propia 
Figura 3. Área de paisaje de agricultura periurbana (APAP) Senia
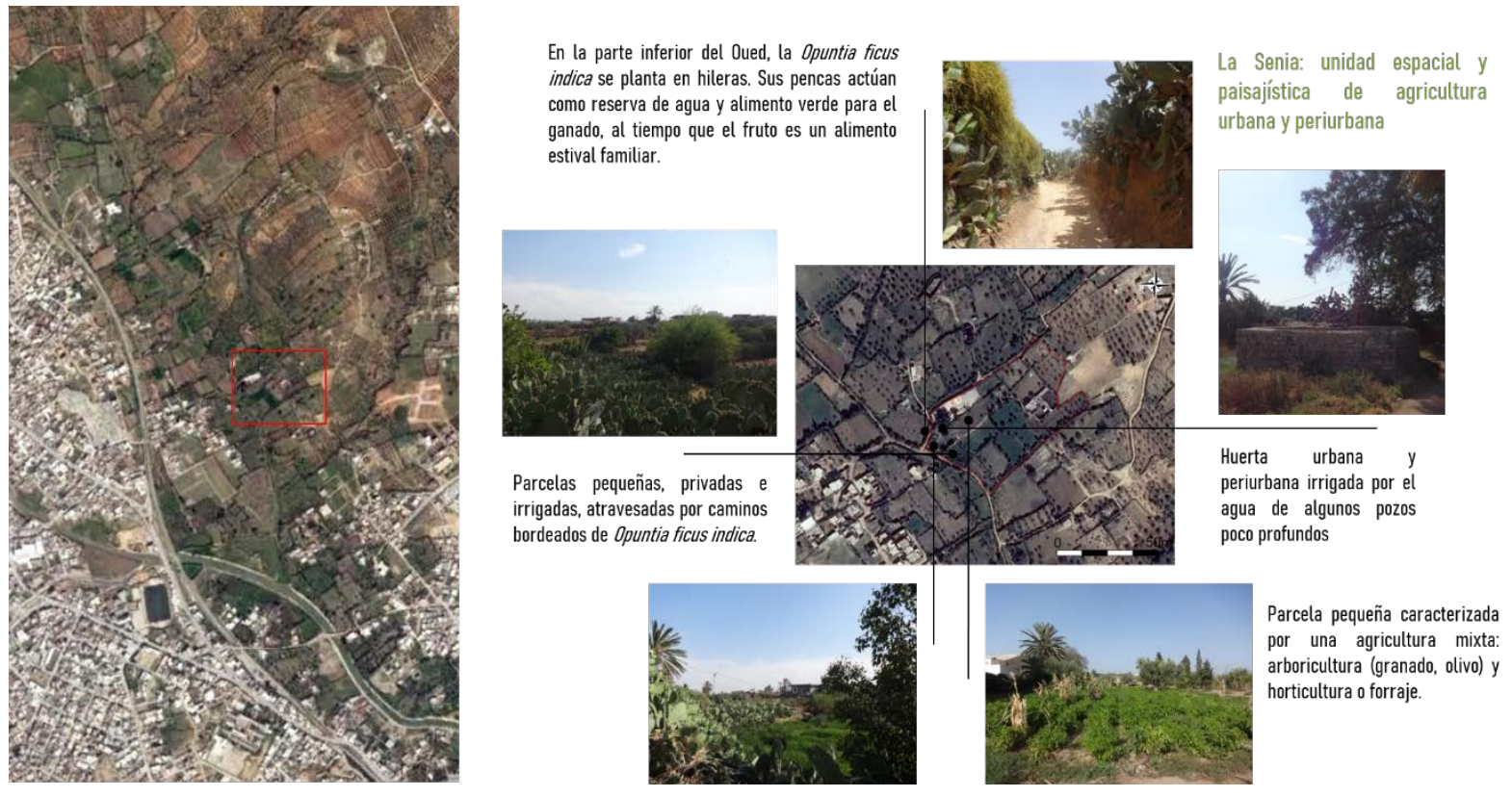

Fuente: elaboración propia a partir de una ortoimagen de Google Earth

\section{La declaración de Parque agrario para la gestión de la zona de riego público de Chott Mariem}

El espacio agrario del entorno de la aglomeración del Gran Sousse, con la diversidad paisajística que se ha señalado, es el marco de importantes cambios resultantes de la presión urbana, la propia dinámica interna de los sistemas agrarios y la difusión de nuevas funciones de la agricultura (Ellomi, 2011). La agricultura periurbana está estrechamente vinculada a la ciudad como oportunidad, pero también como una amenaza sobre su organización, sobre las estrategias de resistencia de los agricultores y sobre la gestión de los recursos naturales (tierra, agua, trabajo y otros factores de producción) (Rejeb, 2011). En todo caso, los espacios periurbanos tunecinos han conocido un cambio muy importante en su estructura social, actividades, uso del suelo, y en la propia organización del sistema productivo (Hammemi \& Sai, 2008). En este tipo de áreas, el alto crecimiento demográfico (una media de 2,6\% al año) incrementa la demanda de suelos para la construcción residencial y de otro tipo; de hecho, el espacio agrario periurbano del Gran Sousse está en el centro de los procesos de urbanización y las Zonas de riego público constituyen probablemente el mejor ejemplo para analizar esta dinámica de cambio. En concreto, la Zona de riego público de Chott Mariem presenta este problema de urbanización extensiva (Figura 4), al que se suma, en ocasiones sin límites claros, el desarrollo del sector turístico (la primera actividad económica de la región), que incide 
directamente en el precio de la tierra, actualmente entre 500 y 1000 DT/m². Esta urbanización turística plural (centros comerciales, restaurantes, hoteles y apartamentos, edificios residenciales】) mal resuelta desde el punto de vista jurídico, técnico y financiero, ejerce una fuerte presión económica y social, a veces insoportable, sobre la tierra, la actividad agraria y los equipamientos urbanos. Los recursos hídricos (el agua de riego) y edáficos son otros de los problemas de esta Zona de riego público, por la explotación insostenible del acuífero (bajo la incidencia del cambio climático) y el agotamiento de los suelos por la explotación excesiva, el uso de productos químicos y la salinidad creciente.

\section{Figura 4. Parcela en venta en la APAP "Zona de riego público" de Chott Mariem}

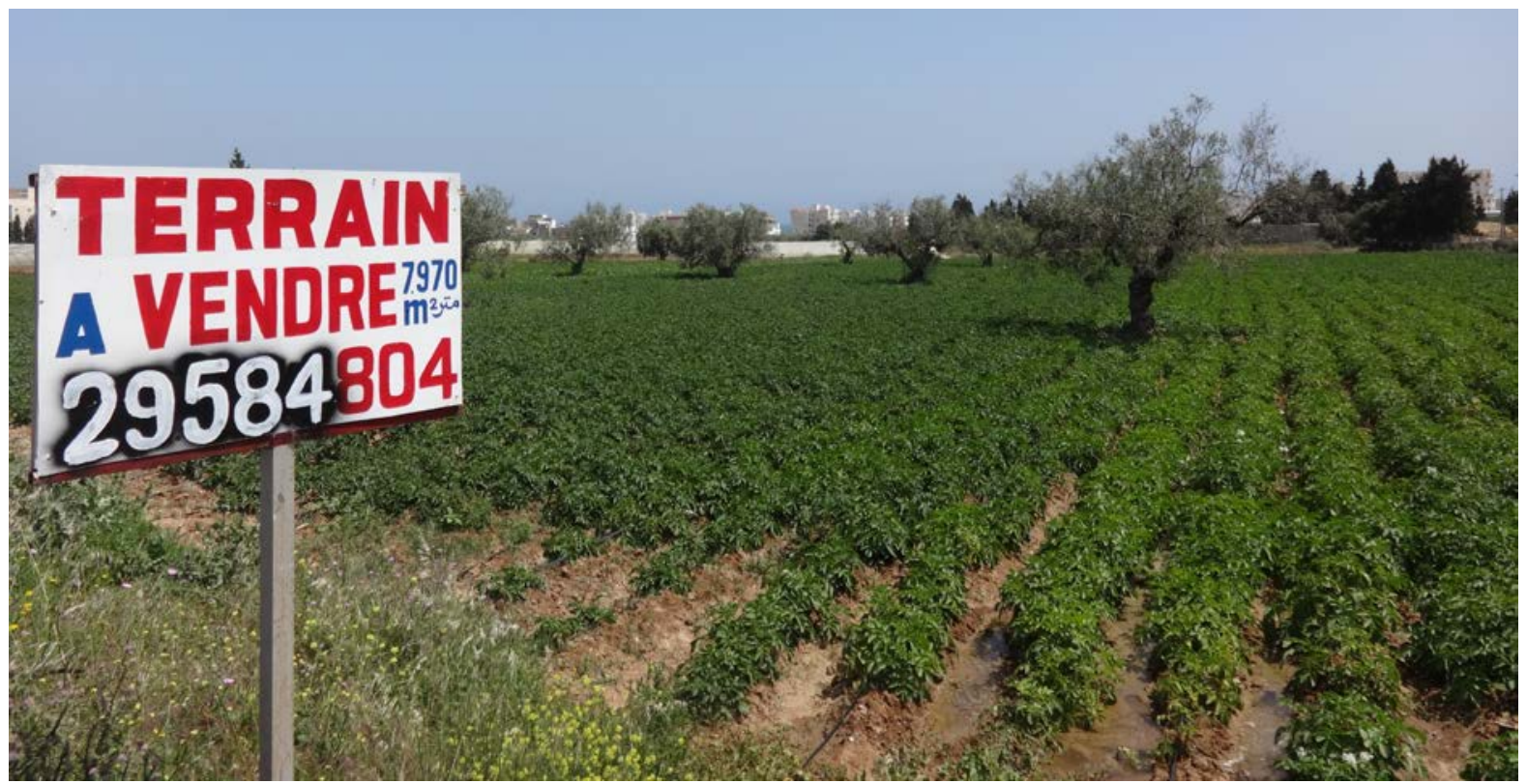

Fuente: elaboración propia

Ante esta fuerte competencia de usos en el Gran Sousse, los conflictos por el aprovechamiento de los recursos, en particular de suelo y agua (Elloumi, 2011; Abdedaien, 2009), y la nueva percepción y demanda social, los poderes públicos buscan un equilibro entre la extensión de la ciudad y la preservación de los espacios agrarios periurbanos, de un alto valor estratégico por la calidad del suelo, la proximidad y la calidad de los productos que aportan y los paisajes que lo gestionan, a través de diversos instrumentos como el plan de ordenación urbana, el plan director de ordenación y la ley de protección de las tierras agrícolas, que presenta hasta ahora un problema de baja aplicación por la existencia de un gobierno frágil. La consideración del Proyecto de Paisaje como una herramienta de planificación y desarrollo en Túnez está completamente ausente. Pero, frente a la insuficiencia e ineficacia de los numerosos intentos de protección de las tierras agrícolas aplicados por las autoridades públicas tunecinas y la creciente 
percepción social del espacio agrario periurbano como un espacio multifuncional, planteamos el proyecto de paisaje como un modelo eficaz para la gestión de conflictos de uso, la ordenación y el fomento de la agricultura periurbana y su paisaje. En nuestra opinión, el proyecto de paisaje, concretado en el proyecto de Parque Agrario, para ser más precisos, puede ser considerado un instrumento que active el regadío periurbano de Chott Mariem (Figura 5).

\section{Figura 5. APAP Zona de riego público de Chott Mariem}

$\begin{array}{ccc}\text { Setos de ciprés como } & & \text { Desarrollo turístico como } \\ \text { elementos característicos del } & \text { El paisaje del regadío público de Chott-Mariem se caracteriza por la } & \text { principal factor de cambio } \\ \text { área paisajística de Chott- } & \text { agricultura mixta y la producción de hortalizas tempranas. } & \begin{array}{c}\text { socioterritorial y paisajístico } \\ \text { en la región. }\end{array}\end{array}$

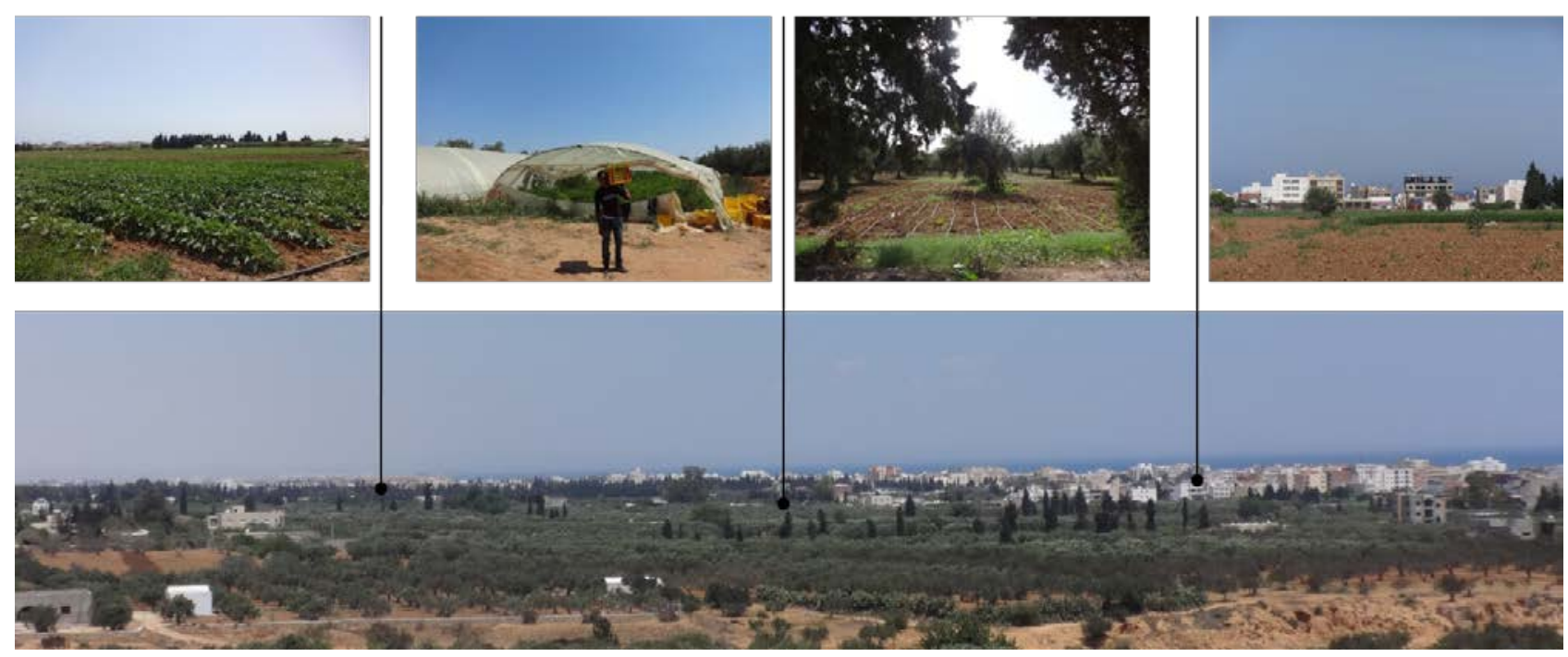

Fuente: elaboración propia

El trabajo de historiadores, geógrafos, agrónomos y especialistas en paisaje ha demostrado que la calidad de muchos paisajes rurales es fruto de proyectos llevados a cabo por sociedades y gobiernos locales y regionales, que han incorporado un enfoque explícitamente paisajístico en sus políticas territoriales y sectoriales agrarias (Ambroise et al., 2001). En este contexto, el Proyecto de Paisaje aparece como resultado principal de esta investigación, considerado como un instrumento que podría activar la agricultura que se desarrolla en la complejidad y la incertidumbre creciente de los espacios periurbanos metropolitanos (Mata-Olmo, 2015; Hamrita et al., 2015). El regadío en aglomeraciones urbano-turísticas, como el caso del Gran Sousse en Túnez, constituye un tipo específico de agricultura periurbana y un ámbito adecuado para la experimentación de las visiones transversales e integradoras de la ordenación y el desarrollo territorial, y la incorporación del proyecto paisajístico contemporáneo. 
La figura del parque agrario podría llegar a ser, con las necesarias adaptaciones de experiencias del norte del Mediterráneo, un proyecto de defensa y activación local de la agricultura periurbana y de su paisaje en la aglomeración urbana de Sousse, y un camino hacia nuevos modelos de gobernanza territorial y alimentaria (Yacamán Ochoa \& Zazo Moratalla, 2015). El objetivo general de un parque agrario es de:

consolidar y desarrollar la base territorial y facilitar la continuidad de la actividad agraria, impulsando programas específicos que permitan preservar los valores (productivos, ecológicos y culturales) y desarrollar las funciones (económica, ambiental y social) del espacio agrario en el marco de una agricultura sostenible integrada en el territorio y en armonía con el medio natural de su entorno (Consorci Parc Agrari del Baix Llobregat, PGD, 1998).

Así, el Parque Agrario de Fuenlabrada (Madrid) (Yacamán Ochoa \& Mata-Olmo, 2017) constituye una buena referencia para concebir un proyecto de paisaje adecuado para las Zonas de riegos públicos de la llanura costera de Sousse y particularmente para la de Chott Mariem, con el objetivo principal de preservar y fortalecer la actividad agraria periurbana y su paisaje, impulsando programas específicos que permitan desarrollar el potencial económico, ambiental y sociocultural del territorio y de sus agentes desde un enfoque multifuncional y agroecológico.

El paisaje de la zona de estudio constituye un eje de valorización y de gestión de la agricultura periurbana, en una ciudad caracterizada por la voluntad de ordenación y desarrollo de su potencial turístico con calidad y marca, para lo que el paisaje de la agricultura periurbana puede constituir un elemento importante. El proyecto del Parque Agrario Local (PAL) de Chott Mariem formará parte del futuro Parque Agrario Regional del Olivar (PARO), que integrará todos los espacios de la agricultura y la naturaleza periurbana (las zonas de riegos públicos, los huertos agrarios patrimoniales, los olivares, las sebkhats[) (Figura 5). El regadío periurbano de Chott Mariem podría ser, por su emplazamiento, actividad y valores, el núcleo de un futuro proyecto de Parque Agrario Local para el fomento de las buenas prácticas agrícolas, la innovación en calidad, la agro-diversidad y la agricultura de proximidad, orientada a la venta directa en las explotaciones y a través de otras vías de comercialización locales. Este proyecto incorporará las estrategias y herramientas innovadoras de gestión y de gobernanza territorial construidas a partir de las diferentes visiones de agentes sociales y administraciones públicas a distintos niveles (local, regional y supra-regional), con el objetivo de avanzar hacia una mayor cohesión y sostenibilidad territorial, basada en la puesta en valor de la multifuncionalidad de sus espacios 
agrarios y su paisaje, en la mejora de la alimentación de los entornos urbanos a través de una oferta de productos frescos, locales, de confianza y producidos por agro-sistemas sostenibles.

El futuro Parque Agrario Local de la Zona de riego público de Chott Mariem en el Gran Sousse exige la participación como base para la construcción de un proyecto de paisaje integrado e integrador (Figura 6). La implicación activa del poder público local, regional y de los actores (agricultores, sector turístico, habitantes, asociaciones】) debe conducir a la construcción de los futuros escenarios de ordenación y desarrollo de una manera participativa. La cooperación entre los distintos actores compromete a los agricultores a producir más y mejor, y a proteger, gestionar y crear paisajes sostenibles. La participación del sector turístico en el proyecto es primordial en una región turística como Sousse, integrándose en las redes de comercialización y consumo de los productos alimentarios y en el uso y el disfrute por parte de los turistas de los paisajes y del patrimonio que albergan. Por el lado de los habitantes, su participación en la puesta en marcha de este proyecto incide en la calidad ambiental, social y paisajística de su marco de vida cotidiano, y en su capacidad educativa y civilizadora; y para los poderes públicos, el proyecto del parque agrario promueve la cohesión económica, social y territorial de la aglomeración metropolitana, y requiere la cooperación y coordinación administrativa.

El proyecto necesita también establecer un modelo de gestión capaz de articular y dinamizar las diferentes iniciativas de desarrollo territorial. El modelo de gestión es la principal herramienta para la preservación de los valores ecológicos, productivos, culturales y paisajísticos del ámbito agrario periurbano del Gran Sousse. De acuerdo con las lecciones aprendidas en otros parques agrarios, los objetivos del modelo de gestión consisten en mejorar la eficiencia de las infraestructuras y los servicios del espacio agrario periurbano, fomentar el desarrollo de una agricultura viable tanto económica como ambientalmente, mejorar la competitividad y la innovación del sector agrario, promover la agricultura de proximidad, generar un territorio multifuncional y un paisaje de calidad, optar por la gobernanza y la participación, garantizar la renovación generacional y mejorar la igualdad de oportunidades en el sector agrario y difundir el patrimonio y los recursos del parque agrario. Para facilitar la coordinación entre los diferentes actores del proyecto de parque agrario y para que puedan construir una acción realmente comunitaria, es necesario también establecer un proceso de mediación. Desde esta perspectiva, el mediador puede ser en este caso el Instituto Superior de Ciencias Agronómicas de Chott Mariem, que tiene que (i) facilitar el debate sobre los objetivos y las actuaciones del proyecto y considerar el punto de visto de cada actor; (ii) ayudar a los agricultores y a los otros actores a formular sus propuestas y ponerlas en relación con los objetivos del proyecto; y (iii) organizar la 
discusión entre los diferentes actores y sintetizar las ideas de todos. Así, en ausencia de espacios naturales en la región de Sousse (sólo las sebkhats o albuferas), el compromiso de los actores locales para elaborar una estrategia de ordenación del espacio agrario con una función de infraestructura verde metropolitana es cada vez más importante. Esta red debe integrar territorial y ecológicamente áreas naturales en la periferia de la región urbana y áreas de agricultura periurbana, en particular las zonas de regadío público sujetas a una planificación estratégica, diseñadas y gestionadas con finalidad agroalimentaria, de producción de una amplia gama de servicios ambientales y de contribución a la política regional de desarrollo territorial sostenible.

Figura 6. Boceto del Proyecto de Paisaje de la región del Gran Sousse

\section{EL PROYECTO DE PAISAJE}

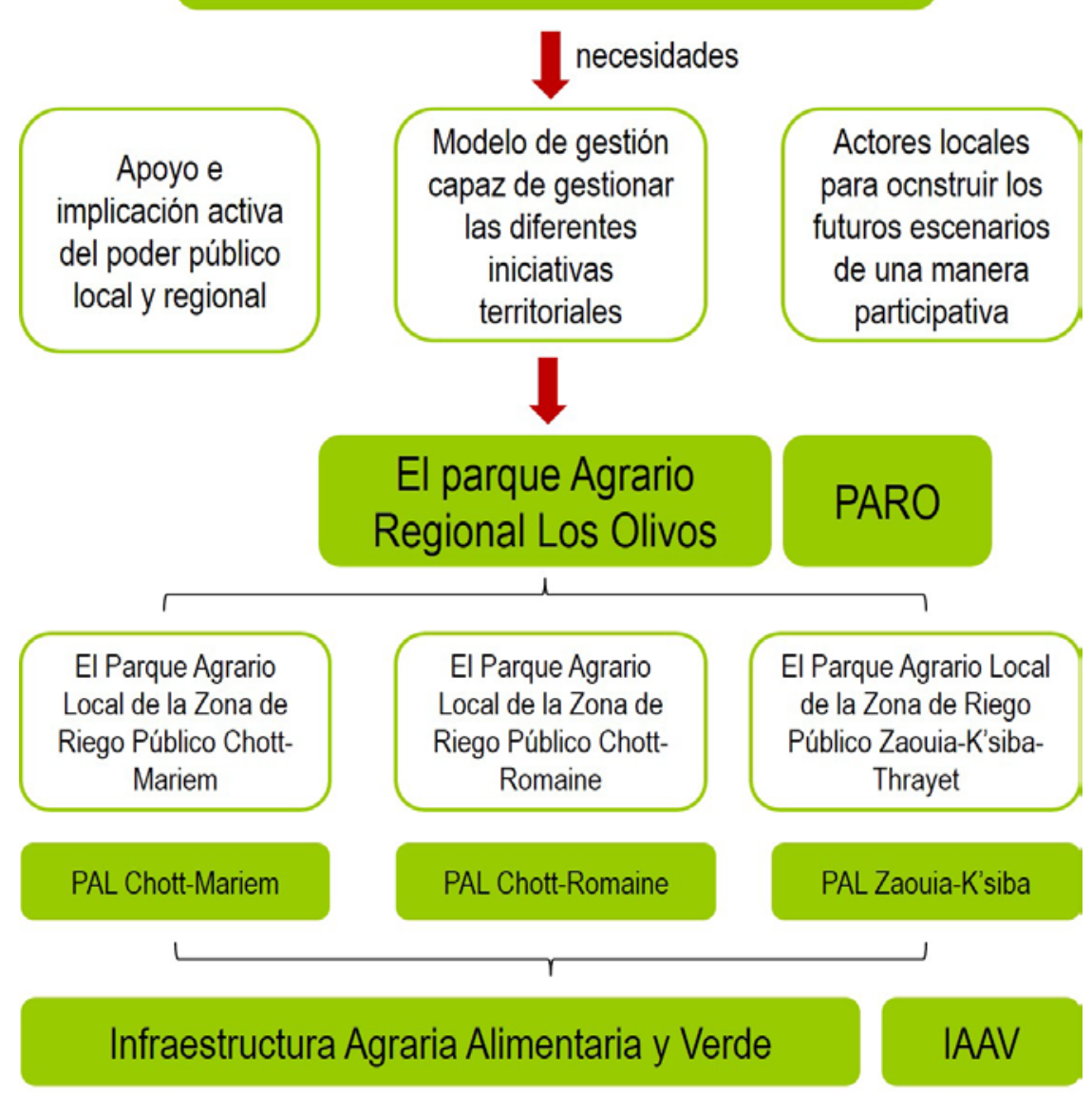

Fuente: elaboración propia

\section{Conclusiones}

El paisaje agrario periurbano del Sahel en general y del Gran Sousse en particular se ha estructurado durante mucho tiempo en torno a la trilogía olivicultura, fruticultura y horticultura. En 
términos superficiales, pero también simbólicos e identitarios, el predominio corresponde al cultivo de olivos, que se adapta a las condiciones geoedáficas y climáticas de la región. El sistema de producción de olivicultura extensiva genera un gran "bosque de olivos" en torno a los espacios urbanos, desarrollado gracias al meskat, que encierra técnicas y adaptaciones al medio propias del saber hacer tradicional. El análisis paisajístico realizado en la zona de estudio pone de manifiesto la permanencia de la trilogía citada, que ha resistido a numerosos conflictos de uso y problemas climáticos y edáficos, asegurando hoy una multifuncionalidad importante en términos de seguridad alimentaria, agrobiodiversidad y conservación de los recursos y el paisaje, al mismo tiempo que mantiene la doble actividad, urbana y rural, y los sistemas de producción combinados y a veces atípicos (floricultura) que promueve la agricultura periurbana.

En ese marco, el proyecto de paisaje es una alternativa de reflexión y proyectual sobre la agricultura periurbana, que permite a los agricultores y a los habitantes construir la "ciudadpaisaje". Es necesario invertir la estrategia clásica de ordenación y pensar y desarrollar la ciudad a partir de los espacios libres de la agricultura periurbana, para establecer una estrategia territorial global que de protagonismo a estos espacios como articuladores de la "ciudadterritorio". El proyecto de formular y desarrollar un parque agrario en la Zona de riego público de Chott Mariem vincula los objetivos de la agricultura y del urbanismo definidos a través de la participación de los actores, con el fin de establecer las directrices que respondan al logro de los objetivos de ese proyecto de ordenación y activación del espacio agrario. El proyecto necesita el apoyo y la implicación de todos los actores; en cuanto a los poderes públicos, su papel consiste en la consideración y aceptación del proyecto de parque agrario como un nuevo instrumento de ordenación y desarrollo económico del espacio agrario periurbano y de su paisaje. La gobernanza es sin duda la forma más coherente de intervenir a escala local, sobre todo cuando se pretende actuar en espacios vivos, con una importante carga cultural y un papel activo de la comunidad agraria en la gestión de su territorio. Trabajar la gobernanza desde un enfoque multi-actor y multinivel supone un importante desafío, partiendo de la base de que, en general, no existen canales de participación y decisión sobre las políticas ligadas al territorio, en especial de la agraria, y ante la pasividad de una parte aún importante de la sociedad civil tunecina en cuestiones tan relevantes como las relacionadas con la calidad de los alimentos, su procedencia, cómo se producen y cuál es su impacto sobre el territorio. Como han señalado ya Rafael Mata y Carolina Yacamán (2014), para lograr un proyecto territorial coherente de protección y dinamización de los espacios agrarios periurbanos y su vinculación con el proyecto de ciudad, deben darse al menos tres circunstancias en materia de participación y gestión: en 
primer lugar, que los poderes públicos locales se impliquen activamente; en segundo, que exista una figura de gestión capaz de catalizar las diferentes iniciativas del territorio; y, por último, que los agentes locales estén dispuestos a construir escenarios de futuro de manera compartida. Conviene incidir también en la necesidad de una figura de gestión lo más inclusiva y horizontal posible, creada expresamente para resolver los conflictos de los espacios agrarios periurbanos y para dinamizar al mismo tiempo las diferentes propuestas de los agentes del territorio, en definitiva, para implementar procesos concretos de gobernanza. Nos parece que la figura del Parque Agrario, de acuerdo con la experiencia y lecciones aprendidas en determinados entornos metropolitanos del norte del Mediterráneo, debería ser el camino a seguir.

Declaración responsable: Los autores y la autora declaran que no existe ningún conflicto de interés con relación a la publicación de este artículo. Las tareas se han distribuido de la siguiente manera: el artículo ha sido coordinado por Abdelkarim Hamrita y Rafael Mata. Los tres autores y la autora han participado en la revisión bibliográfica y la redacción del artículo. La elaboración de la cartografía y las figuras han estado a cargo de A. Hamrita. 


\section{Bibliografía}

Abdedaiem, S. (2009). Mutations socio-agro-économiques et modes de gouvernance de l'eau dans les oasis périurbaines du gouvernorat de Gabès (Doctoral dissertation, Université de ParisNanterre, France). Retrieved from http://www.theses.fr/2009PA100035

Agamben, G. (1998). HomoSacer: Sovereing Power and Bare Life. Stanford: Stanford University Press.

Ambroise, R., Bonneaud, F., \& Brunet-Vinck, V. (2001): Paysage et agriculture: un nouveau projet. Aménagement et Nature, 141, 29-41. Retrieved from

http://hdl.handle.net/2042/48839

Ambroise, R., \& Toublanc, M. (2015). Paysage et agriculture pour le meilleur. France: Educagri.

Ávila, C. (2011). Proyectos de paisaje y medio ambiente urbano. In I. Alday et al. (eds.), Proyectos integrados de arquitectura, paisaje y urbanismo (pp. 176-187). Zaragoza: Universidad de Zaragoza.

Bastian, O., Grunewald, K., Syrbe, R.-U., Walz, U., \& Wende, W. (2014). Landscape services: the concept and its practical relevance. Landscape Ecology, 29, 1463-1479.

Ben Attia, O. (2015). Agriculture urbaine face à I'urbanisme non organisé du périmètre public irrigué de ChottMariem. In H. Rejeb (Ed.), Alternatives éco paysagères dans les régions méditerranéennes (pp 53-62). Sousse, Ouvrage Interuniversitaire Transdisciplinaire à Comité de Lecture Internationale, 13.

Bergera, I. (2011). Nuevos paisajes, nuevas miradas. In I. Alday et al. (eds.), Proyectos integrados de arquitectura, paisaje y urbanismo (pp. 14-28). Zaragoza: Universidad de Zaragoza.

Bouraoui, M. (2001). L'agriculture, nouvelinstrument de la constructionurbaine? Etude de deux modèles agri-urbains d'aménagement du territoire: le plateau de Saclay à Paris, et la plaine de Sijoumi à Tunis. Ruralia, 8. Retrieved from http://journals.openedition.org/ruralia/223.

Branduini, P., \& Scazzosi, L. (2011). Les paysages agraires périurbains: vers la Co-construction du territoire. Les Cahiers du Développement Urbain Durable, 12, 39-66. Retrieved from https://www.researchgate.net/publication/258769878_Les_paysages_agraires_periurbain s_vers_la_co-_construction_du_territoire 
Bryant, C. R. (1997). L'agriculture périurbaine. L'économie d'un espace innovateur. Cahiers Agricultures, 6, 125-30. Retrieved from https://revues.cirad.fr/index.php/cahiersagricultures/article/view/29999

Callau, S., \& Paül, V. (2007). Le parc agricole du Baix Llobregat: un moyen de préserver, développer et gérer un espace agricole périurbain. In A. Fleury (Ed.), Les agricultures périurbaines. Un enjeu pour la ville, en Actes du colloque international de Nanterre, 2 (pp. 1-15). Retrieved from http://www.rolandvidal.fr/recherche/colloque-nanterre/actes-volume-2/

Comete Engineering (2000). Etude de diagnostic et de modernisation de l'exploitation des périmètres irrigués dans le Gouvernorat de Sousse. Retrieved from http://www.cometegroup.com/En/projects_59_18_D12

Consejo de Europa (2000). Convenio europeo del paisaje. Florencia 20-x-2000. Retrieved from https://rm.coe.int/CoERMPublicCommonSearchServices/DisplayDCTMContent?document $\underline{\mathrm{ld}=0900001680080621 .}$

Comisión Europea (2013). Comunicación de la Comisión al Parlamento Europeo, al Consejo, al Comité Económico y Social Europeo y al Comité de las Regiones. Infraestructura Verde: mejora del capital natural de Europa. Retrieved from https://eurlex.europa.eu/resource.html? uri=cellar:d41348f2-01d5-4abe-b817-

4c73e6f1b2df.0008.03/DOC_1\&format=PDF

Consorci Parc Agrari del Baix Llobregat (Ed.) (1998). Plan de Gestión y Desarrollo de Parc Agrari del Baix Llobregat. Diputació de Barcelona. Xarxa de Municipios, Barcelona. Retrieved from https://parcs. diba.cat/documents/170508/5108900/p09d113.pdf

Desvignes, M. (2006). La Charte des Paysages de la Ville de Bordeaux, Direction Générale de I'Aménagement Urbain de la Ville de Bordeaux. Retrieved from http://www.bordeaux.fr/p8351/la-charte-des-paysages

Donadieu, P., \& Rejeb, H. (2009). Abrégé de géo-médiation paysagiste. Tunisie: Imprimerie Officielle Tunisienne.

Donadieu, P. (2009). Aceptaron as sociedades rurais europeas as políticas paisaxísticas públicas? In F. Díaz-Fierros \& F. López Silvestre (Coords.), Olladas críticas sobre a paisaxe, Santiago de Compostela (pp. 267-283). Consello da Cultura Galega. Retrieved from http://consellodacultura.gal/publicacion.php?id=563 
Ellomi, M. (2011). Agriculture périurbaine et nouvelles fonctions du foncier rural en Tunisie. In M. Elloumi et al. (Eds.), Régulation foncière et protectiondes terres agricoles en Méditerranée. Montpellier. Retrieved from http://om.ciheam.org/article.php?IDPDF=801381

Fernández Álvarez, R. (2010). La aplicación de Landscape Character Assessment a los espacios de montaña media: el paisaje del macizo de las Villuercas. Ciudad y territorio, Estudios Territoriales, 185, 499-518. Retrieved from

https://recyt.fecyt.es/index.php/CyTET/article/view/76427.

Fleury, A., \& Donadieu, P. (1997). De l'agriculture péri-urbaine à l'agriculture urbaine. Le Courrier de l'environnement de I'INRA, 31, 45-61. Retrieved from https://hal.archivesouvertes.fr/hal-01204863

Franchi, A. (Coord.) (2015). Les Atlas de paysages: Méthode pour l'identification, la caractérisation et la qualification des paysages. Paris: Ministère de l'Écologie, du Développement durable et de l'Énergie française. Retrieved from http://www.bv.transports.gouv.qc.ca/mono/1168220.pdf

Giacche, G., Torquati, B., Scazzosi, L., \& Branduini, P. (2012, January 4). Le pacte agriurbain de la vallée ombrienne et les districts agricoles et culturels de Milan. Deux modèles de gestion des espaces agricoles périurbains. Projet de Paysage. Retrieved from http://www.projetsdepaysage.fr/fr/le_pacte_agriurbain_de_la_vallee_ombrienne_et_les_d istricts_agricoles_et_culturels_de_milan_.

Giacché, G., \& Mazzocchi, C. (2011, July 20). Gli instrumenti di pianificazio territoriale in relazione alla funcionalità dell'agricoltura peiurbana. Projet de paysage. Retrieved from http://www.projetsdepaysage.fr/fr/gli_strumenti_di_pianificazione_territoriale_in_relazion e_alla_funzionalita_dell_agricoltura_periurbana_

Hammami, M., \& Sai, M.E. (2008). Problèmes fonciers et agriculture périurbaine dans le grand Tunis: Mutations foncières et stratégies des agricultures. New Medit, 7(1), 58-64. Retrieved from https://newmedit.iamb.it/share/img_new_medit_articoli/14_58hammami.pdf

Hammami Habibi, S. (2010). Territoires de projets et agriculture multifonctionnelle sur le littoral tunisien; cas de la façade orientale du Cap Bon (Doctoral dissertation, ISA Chott-Mariem). Retrieved from http://www.secheresse.info/spip.php?article50398

Hamrita, A., Mata-Olmo, R., \& Rejeb, H. (2015). L'itinéraire paysager: une nouvelle alternative par et pour le paysage. In $\mathrm{H}$. Rejeb (Ed.), Alternatives éco paysagères dans les régions 
méditerranéennes (pp. 187-200). Ouvrage Interuniversitaire Transdisciplinaire à Comité de Lecture Internationale.

Retrieved from https://www.researchgate.net/publication/353368863_L'TIINERAIRE_PAYSAGER_UNE_N OUVELLE_ALTERNATIVE_PAR_ET_POUR_LE_PAYSAGE

Hermosilla Pla, J. (Dir.) (2010). Los regadíos históricos españoles. Paisajes culturales, paisajes sostenibles. Madrid: Ministerio de Medio Ambiente y Medio Rural y Marino.

Houimli, E. (2008). Les facteurs de résistance et de fragilité de l'agriculture littorale face à I'urbanisation: le cas de la région de Sousse nord en Tunisie (Doctoral dissertation, ISA-Chott Mariem, Tunisia). Retrieved from https://tel.archives-ouvertes.fr/pastel-00004488/

Hurni, J. (2004). Is Landscape Character Assessment the work of public policy. In De la connaissance des paysages à l'action paysagère. Bordeaux: Cemagref y Ministere Ecologie Developpement Durable France.

Lofrberg, F., Licka, L., Scazzosi, L., \& Timpe, A. (Eds.) (2016). Urban Agriculture Europe. Berlin: Jovis Verlag $\mathrm{GmbH}$.

Maderuelo, J. (2005). El paisaje: génesis de un concepto. Madrid: Abada.

Mata-Olmo, R. (2006). Métodos de estudio del paisaje e instrumentos para su gestión. Consideraciones a partir de experiencias de planificación territorial, In R. Mata-Olmo \& A. Tarroja (Eds.), El paisaje y la gestión del territorio. Criterios paisajísticos en la ordenación del territorio y el urbanismo. Barcelona: Diputació de Barcelona-UIMP (pp. 199-239).

Mata-Olmo, R. (2004). Agricultura, paisaje y gestión del territorio, Polígonos. Revista de Geografía, 14, 97-137. Retrieved from http://dx.doi.org/10.18002/pol.v0i14.492

Mata-Olmo, R. (2011). A vibrant agriculture system for a quality periurban landscape. In Catalogue of Good Practices for the Landscape in Periurban Areas and Third Edition of the Mediterranean Landscape Award 2011 (PAY.MED.URBAN PROJECT 2007-2013) (pp. 192-196). Murcia: Consejería de Obras Públicas y Ordenación del Territorio.

Mata-Olmo, R. (2014). El Convenio Europeo del Paisaje del Consejo de Europa. Notas sobre su aplicación en España. Patrimonio cultural y Derecho, 18, 8-21. Retrieved from https://www.researchgate.net/publication/336881036_El_Convenio_Europeo_del_Paisaje _del_Consejo_de_Europa_Notas_sobre_su_aplicacion_en_Espana

Mata-Olmo, R. (2015). Reflexiones en torno a la valoración y gestión del paisaje en los parques agrarios, In C. Yacamán \& A. Zazo (Ed.), El parque Agrario, una figura de transición hacia 
nuevos modelos de gobernanza territorial y alimentaria. Madrid: Heliconia (pp. 185-162). Retrieved from https://www.heliconia.es/wp-content/uploads/2015/10/ParqueAgrario_Yacam\%C3\%A1n-Zazo.pdf

Mata-Olmo, R., \& Fernández Muñoz, S. (2010). Paisajes y patrimonios culturales del agua. La salvaguarda del valor patrimonial de los regadíos tradicionales. Scripta Nova, 337. Retrieved from https://revistes.ub.edu/index.php/ScriptaNova/article/view/1642

Mata-Olmo, R., \& Yacamán Ochoa, C. (2015). Gobernanza para una agricultura viva en un paisaje periurbano de calidad. Estudios de caso en la huerta Metropolitana de Madrid, In: XXIV Congreso de la Asociación de Geógrafos Españoles, Universidad de Zaragoza. Retrieved from http://congresoage.unizar.es/eBook/trabajos/028_Mata\%200lmo.pdf

Meddeb, S. (2009). Les capacités de résistances des agricultures périurbaines face au processus de métropolisation (Doctoral dissertation, University of Toulusse II, France \& ISA-CM, Tunisia) (Unpublished).

Monclús Fraga, J. (2011). Paradigmas urbanísticos y proyectos integrados. Entre el urbanismo arquitectónico y el ecourbanismo paisajístico. In I. Alday et al. (Eds.), Proyectos integrados de arquitectura, paisaje y urbanismo (pp. 42-59). Zaragoza: Universidad de Zaragoza. Retrieved from https://ifc.dpz.es/recursos/publicaciones/31/76/04monclus.pdf

Montasell, J., \& Zazo Moratalla, A. (2015). Todo gran cambio empieza con preguntas. Diez cuestiones para un proyecto agro-urbano: de lo necesario a lo posible. In C. Yacamán Ochoa \& A. Zazo Moratalla (Eds.), El parque agrario: Una figura de transición hacia nuevos modelos de gobernanza territorial y alimentaría (pp. 29-36). Madrid, Heliconia. Retrieved from https://www.heliconia.es/wp-content/uploads/2015/10/ParqueAgrario_Yacam\%C3\%A1n-Zazo.pdf

Montasell, J., \& Callau, S. (2015). Células alimentarias: Un nuevo instrumento de planificación y gestión de sistemas agro-urbanos, In C. Yacamán Ochoa \& A. Zazo Moratalla (Ed.), El parque agrario: Una figura de transición hacia nuevos modelos de gobernanza territorial y alimentaría (pp. 143-164). Madrid: Heliconia. Retrieved from https://www.heliconia.es/wpcontent/uploads/2015/10/Parque-Agrario_Yacam\%C3\%A1n-Zazo.pdf

Mostafavi, M. (2010). Why Ecological Urbanism? Why Now? In M. Mustafavi \& G. Doherty (Eds.), Ecological Urbanism (pp. 12-51). Harvard University Graduate School of Desing \& Lars Müller Publishers. 
Paül, V. (2015). Los Parques Agrarios en Cataluña. Breve análisis de la contribución de Josep Montasell a su concepción, desarrollo e implantación, In C. Yacamán Ochoa \& A. Zazo Moratalla (Eds.), El parque agrario: Una figura de transición hacia nuevos modelos de gobernanza territorial y alimentaría (pp. 113-142). Madrid: Heliconia. Retrieved from https://www.heliconia.es/wp-content/uploads/2015/10/ParqueAgrario_Yacam\%C3\%A1n-Zazo.pdf

Paül Carril, V., \& Haslam McKenzie, F. (2013). Peri-urban farmland conservation and development of alternative food networks: Insights from a case-study area in metropolitan Barcelona (Catalonia, Spain). Land Use Policy, 30, 94-105. Retrieved from https://www.sciencedirect.com/science/article/pii/S0264837712000294

Poulot, M. (2014). L'invention de l'agri-urbain en Île-de-France. Quand la ville se repense aussi autour de l'agriculture? Géocarrefour, 89(1-2-3), 11-19. Retrieved from

http://geocarrefour.revues.org/9363

Roda, R. (2015). Reflexiones en torno al ente gestor como figura de gobernanza. In C. Yacamán Ochoa \& A. Zazo Moratalla (Coords.), El Parque Agrario: una figura de transición hacia nuevos modelos de gobernanza territorial y alimentaria (pp. 37-54). Madrid: Heliconia. hitps://www.heliconia.es/wp-content/uploads/2015/10/ParqueAgrario_Yacam\%C3\%A1n-Zazo.pdf

Romero, J., \& Francés, M. (Eds.) (2012). La Huerta de Valencia: un paisaje cultural con futuro incierto. Valencia: Publicacións de la Universitat de València.

Silva Pérez, R. (2009). Agricultura, paisaje y patrimonio territorial. Los paisajes de la agricultura vistos como patrimonio. Boletín de la Asociación de Geógrafos Españoles, 49, 309-334. Retrieved from https://bage.age-geografia.es/ojs/index.php/bage/article/view/786/709

Piqueras Haba, J. (2009). La agricultura. In J. Hermosilla (Coord.), La ciudad de Valencia: historia, geografía y arte de la ciudad de Valencia. Geografía y Arte, Las actividades económicas y los transportes. Siglos XX y XXI, 2 (pp. 187-208). Retrieved from http://hdl.handle.net/10550/28653

Rejeb, H. (2011). Les enjeux de l'agriculture urbaine et périurbaine en Tunisie. Revue Lettre de Veille-Agricultures urbaines en Méditerranée, 18, 5-7.

Roda, R. (2015). Reflexiones en torno al ente gestor como figura de Gobernanza (Diputación de Barcelona, Gerente del ParcAgrari del Baix Llobregat). In C. Yacamán Ochoa \& A. Zazo 
Moratalla (Eds.), El parque agrario: Una figura de transición hacia nuevos modelos de gobernanza territorial y alimentaría (pp. 37-54). Madrid: Heliconia. Retrieved from https://www.heliconia.es/wp-content/uploads/2015/10/Parque-

Agrario_Yacam\%C3\%A1n-Zazo.pdf

Sabaté, J. (2015). Reflexiones en torno al proyecto urbanístico de un Parque Agrario. In C. Yacamán Ochoa \& A. Zazo Moratalla (Eds.), El parque agrario: Una figura de transición hacia nuevos modelos de gobernanza territorial y alimentaría (pp. 93-111). Madrid: Heliconia. Retrieved from

https://www.heliconia.es/wp-content/uploads/2015/10/Parque-Agrario_Yacam\%C3\%A1n-

\section{Zazo.pdf}

Sonnino, R. (2016). The new geography of food security: exploring the potential of urban food strategies: The new geography of food security. The Geographical Journal, 182(2), 190-200. Retrieved from https://rgs-ibg.onlinelibrary.wiley.com/doi/pdfdirect/10.1111/geoj.12129

Swanwick, C. (2002). Landscape Character Assessment. Guidance for England and Scotland. The Countryside Agency and Scottisch Natural Heritage. Retrieved from https://www.nature.scot/sites/default/files/2018-02/Publication\%202002\%20\%20Landscape\%20Character\%20Assessment\%20guidance\%20for\%20England\%20and\%20Scotl and.pdf

Termorshuizen J.W., \& Opdam P. (2009). Landscape services as a bridge between landscape ecology and sustainable development. Landscape Ecology, 24, 1037-1052.

Tudor, Ch. (2014) [2002]. An Approach of Landscape Character Assessment, Natural England, London. Retrieved from http://www.hwa.uk.com/site/wpcontent/uploads/2017/10/CDF.18_An-Approach-to-Landscape-Character-Assessment_NaturalEngland_October-2014.pdf

Vidal, A., \& Fleury, A. (2009). La place de l'agriculture dans la metropole verte. Nostalgies, utopies et realités dans l'aménagement des territoires aux franges urbaines. Projets de paysage. Retrieved from

http://www.projetsdepaysage.fr/fr/la_place_de_I_agriculture_dans_la_metropole_verte

Waldheim, C. (2010). Notes towards a history of agrarian urbanism. In M. White \& $M$. Przybylski (Eds.), On farming (pp. 18-24). Actar: New York-Barcelona. 
Yacamán Ochoa, C. (2015). Reflexiones sobre la gestión y la dinamización de los Parques Agrarios: democratizando el sistema agroalimentario. In C. Yacamán Ochoa \& A. Zazo Moratalla (Eds.), El parque agrario: Una figura de transición hacia nuevos modelos de gobernanza territorial y alimentaría (pp. 37-54). Madrid, Heliconia. Retrieved from https://www.heliconia.es/wpcontent/uploads/2015/10/Parque-Agrario_Yacam\%C3\%A1n-Zazo.pdf

Yacamán Ochoa, C., \& Mata-Olmo, R. (2014). La gobernanza territorial y alimentaria como base para la protección y dinamización del espacio agrario periurbano. Estudio de caso del parque agrario de Fuenlabrada (Comunidad de Madrid). In XVII Coloquio de Geografía Rural Colorural 2014. Revalorizando el espacio rural: leer el pasado para ganar el futuro (pp. 275-288). Girona: Documenta Universitaria. Retrieved from

https://www2.udg.edu/Portals/3/colorural/XVII\%20Coloquio\%20de\%20Geografia\%20Rural. $\underline{\mathrm{pdf}}$

Yacamán Ochoa, C., \& Mata-Olmo, R. (2017). Huerta y campos de Fuenlabrada. Un paisaje agrario con historia y futuro. Madrid: Heliconia. Retrieved from https://heliconia.es/wpcontent/uploads/2017/10/Yacaman_Mata_web2.pdf

Yacamán Ochoa, C., \& Zazo Moratalla, A. (2015). El parque agrario: Una figura de transición hacia nuevos modelos de gobernanza territorial y alimentaría. Madrid: Heliconia (pp. 226). Retrieved from https://www.heliconia.es/wp-content/uploads/2015/10/ParqueAgrario_Yacam\%C3\%A1n-Zazo.pdf

Yacamán Ochoa, C., Sanz Sanz, E., \& Mata-Olmo, R. (2020). Agricultura periurbana y planificación territorial. De la protección al proyecto agrourbano. Valencia: Publicacions de la Universitat de València.

Zasada, I. (2011). Multifunctional peri-urban agriculture-A review of societal demands and the provision of goods and services by farming. Land use policy, 28(4), 639-648.

Zazo Moratalla, A. (2015). Reflexiones sobre la protección de la base territorial del Parque Agrario: la institucionalización de su espacio agrario periurbano. In C. Yacamán Ochoa \& A. Zazo Moratalla (Eds.), El parque agrario: Una figura de transición hacia nuevos modelos de gobernanza territorial y alimentaría (pp. 73-92). Madrid: Heliconia. Retrieved from https://www.heliconia.es/wp-content/uploads/2015/10/ParqueAgrario_Yacam\%C3\%A1n-Zazo.pdf 
Zoido Naranjo, F., \& Ortega Delgado, M. (Dirs.) (2010). Marco conceptual y metodológico para los paisajes españoles. Sevilla: Junta de Andalucía.

Zubelzu Mínguez, S., \& Allende Álvarez, F. (2014). El concepto de paisaje y sus elementos constituyentes: requisitos para la adecuada gestión del recurso y adaptación de los instrumentos legales en España. Cuadernos de Geografía, Revista Colombiana de Geografía, 24(1), $29-42$. Retrieved from hittps://dialnet.unirioja.es/descarga/articulo/5006009.pdf 